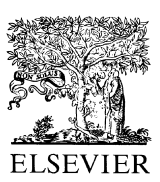

\title{
Thrombelastographic Evidence of Hyperfibrinolysis During Liver Transplantation for Familial Amyloidotic Polyneuropathy ATTR Met $\mathbf{3 0}$
}

\author{
J.S. Viana, M.G. Pereira, L. Lozano, H. Vieira, A. Palmeiro, M. Lourenço, C.A. Tavares, C. Seco, \\ S. Neves, C. Bento, R. Perdigoto, C. Ferrer-Antunes, A.L. Craveiro, and L. Furtado
}

$\mathrm{F}$ AMILIAL amyloidotic polyneuropathy (FAP) ATTR Met 30 is the result of an inherited disorder of transthyretin metabolism. Both amyloid transthyretin and normal transthyretin are produced in the liver and the transplantation is a successful therapy for this disease and is performed in spite of the completely normal liver function of these patients. ${ }^{1}$ A high incidence of hyperfibrinolysis was reported during liver transplantation but these studies were performed in patients with previous liver insufficiency and the relative role of preoperative factors (liver disease, coagulation disorders, increased fibrinolytic activity) and intraoperative factors (surgical trauma, hypotension, and graft reperfusion) is not clearly established. ${ }^{2,3}$ As far as we know, the incidence and the severity of hyperfibrinolysis during liver transplantation in patients without preoperative liver insufficiency has not yet been studied. The aim of this study was to evaluate the incidence of hyperfibrinolysis during liver transplantation in FAP and to correlate these findings with several perioperative factors.

\section{PATIENTS}

Group I included 75 FAP ATTR Met 30 recipients of first liver transplants during a 6-year period, 41 male and 34 female, with age of $35.1 \pm 7.2$ years, body mass index (BMI) of $20.7 \pm 4.1 \mathrm{~kg} / \mathrm{m}^{2}$, disease duration (since the first symptom) of $4.4 \pm 2.4$ years and neurologic score of $32.7 \pm 11.3$ in the scale of Macedo et al. ${ }^{4}$ Every patient in this group received prophylactic antifibrinolytic therapy. For a control, 102 patients with liver diseases transplanted during the same period were used as follows: 21 patients that did not receive prophylactic antifibrinolytic therapy were considered as group IIA; 81 patients that received high-dose aprotinin during all the surgical procedure were considered as group IIB. Not different concerning sex, both group IIA $(43.2 \pm 13.8$ years, $P<.01)$ and group IIB ( $43.2 \pm 12.5$ years, $P<.001)$ were older than group I. Group I patients had normal liver tests: AST, $26.0 \pm 12.2 \mathrm{U} / \mathrm{L}$; ALT, $25.3 \pm 15.7 \mathrm{U} / \mathrm{L}$; total bilirubin $0.8 \pm 0.4 \mathrm{mg} / \mathrm{dL}$; direct bilirubin $0.1 \pm 0.1 \mathrm{mg} / \mathrm{dL}$. The same was not observed in the other groups: AST was $124 \pm 228 \mathrm{U} / \mathrm{L}$ in group IIA $(P=\mathrm{ns})$ and $191 \pm$ $467 \mathrm{U} / \mathrm{L}$ in group IIB $(P<.01)$; ALT, $100 \pm 156 \mathrm{U} / \mathrm{L}$ in group IIA $(P=\mathrm{ns})$ and $169 \pm 419 \mathrm{U} / \mathrm{L}$ in group IIB $(P<.01)$; total bilirubin $5.3 \pm 9.9 \mathrm{mg} / \mathrm{dL}$ in group IIA $(P=\mathrm{ns})$ and $10.1 \pm 12.5 \mathrm{mg} / \mathrm{dL}$ in group IIB $(P<.001)$; direct bilirubin $3.0 \pm 6.5 \mathrm{mg} / \mathrm{dL}$ in group IIA $(P=\mathrm{ns})$ and $5.1 \pm 7.7 \mathrm{mg} / \mathrm{dL}$ in group IIB $(P<.001)$. The values of $P$ account comparisons with group $\mathrm{I}$.

\section{METHOD}

Anesthesia, monitoring, circulatory, and coagulation goals and treatments were the same in the three groups. Thrombelastograms (TEG) were retrospectively evaluated in a blind fashion by two independent observers. As standardized, one intraoperative value of a60/ma (whole blood clot lysis index) less than 0.8 was considered a signal of hyperfibrinolysis. Before the evaluation of any TEG of this study, we decided to consider one intraoperative value of $\mathrm{F}$ (whole blood clot lysis time) less than 60 minutes as evidence of severe hyperfibrinolysis. The three groups were compared by one-way ANOVA followed by Tukey's test. Within group I, patients with hyperfibrinolysis were compared with patients without hyperfibrinolysis by Mann-Whitney U test or chi-square test, followed if necessary by Fisher exact test. Data are presented as mean \pm standard deviation.

\section{RESULTS}

Values of a60/ma less than 0.8 were observed in at least one TEG of 64 patients $(85.5 \%)$ of group I, $13(61.9 \%)$ of group IIA, and $35(43.2 \%)$ of group IIB meaning that group I incidence was significantly different from group IIA $(P<$ $.05)$ and group IIB $(P<.001)$. Values of $\mathrm{F}$ less than 60 minutes were observed in 26 patients $(34.7 \%)$ of group I, none of group IIA, and $1(1.2 \%)$ of group IIB. Group I was also significantly different from group IIA $(P<.01)$ and group IIB $(P<.001)$. The duration of anesthesia was not different in the three groups. Group I patients consumed $5.3 \pm 10.2$ units of red blood cells (RBC), $13.0 \pm 17.6$ units of fresh frozen plasma (FFP), and $3.8 \pm 9.6$ units of platelets. A nonsignificant tendency toward higher values was observed in group IIA: $9.6 \pm 8.3$ units of $\operatorname{RBC}(P=\mathrm{ns})$, $19.5 \pm 16.0$ units of FFP $(P=$ ns $)$ and $5.8 \pm 7.8$ units of platelets $(P \pm \mathrm{ns})$. Significantly higher values were observed in group IIB: $14.5 \pm 14.2$ units of $\operatorname{RBC}(P<.001), 29.2 \pm$

From the Department of Transplantation, Department of Anesthesiology, and Hematology Laboratory, University Hospitals of Coimbra, Coimbra, Portugal.

Address reprint requests to $\mathrm{Dr}$ Joaquim Viana, Department of Anesthesiology, University Hospitals of Coimbra, 3049 Coimbra Codex, Portugal. E-mail: jvviana@huc.min-saude.pt. 
22.7 units of FFP $(P<.001)$, and $9.8 \pm 8.8$ units of platelets $(P<.001)$. One-year actuarial survival in group I $(88.8 \%)$ was higher than in group IIB $(63.8 \%, P<.001)$ but not significantly higher than in group IA $(81.0 \%, P=\mathrm{ns})$. Within group I, when we compared patients with $\mathrm{F}$ less than 60 minutes with the remaining patients of the same group, we observed a higher consumption of RBC $(10.5 \pm 15.9$ vs $2.5 \pm 2.2, P<.001), \mathrm{FFP}(20.4 \pm 9.1$ vs $9.1 \pm 6.8, P<.001)$ and platelets $(8.8 \pm 14.7$ vs $1.1 \pm 2.8, P<.001)$, a longer duration of anesthesia (10:33 hours \pm 3:06 vs 8:52 $\pm 2: 24$, $P<.001)$ and a longer duration of postoperative ventilation $(57.3 \pm 133.8$ hours vs $8.5 \pm 7.8$ hours, $P<.001)$, but not a different perioperative mortality ( $0 \%$ vs $2.0 \% P=\mathrm{ns})$ or a different 1 -year survival $(89.3 \%$ vs $87.7 \%, P=\mathrm{ns})$. When we compared patients with am/a60 less than 0.8 with the other patients of group I, we did not observe any kind of difference.

\section{DISCUSSION}

Our data show that hyperfibrinolysis is a frequent event during liver transplantation for FAP and severe cases have been clearly associated with increase of blood losses, duration of surgery and postoperative ventilation but not with increased mortality. The higher incidence of hyperfibrinolysis in FAP when compared with group IIB is not unexpected as the latter group received prophylactic aprotinin, which is effective in preventing the development of hyperfibrinolysis. ${ }^{5}$ Nevertheless, the significant differences observed between groups I and IIA are rather unexpected. Surgical procedures in group I tend to be less hemorrhagic and, as far as we know, nothing has ever been reported suggesting any relation between FAP and coagulation disorders. Under these circumstances it was expected that FAP patients presented less and not more hyperfibrinolysis when compared with patients with liver diseases. We can hypothesize that our findings could be related with the high incidence of hypotension reported as a frequent complication during liver transplants for FAP. 6,7

Within group I, concerning the relations between TEG signals of severe hyperfibrinolysis and increased consumption of blood products and longer anesthesia duration, it is important to stress that the design of our study did not allow to determine what is cause and what is consequence. Prophylactic antifibrinolytic regimen significantly reduce fibrinolysis during liver transplant, ${ }^{5,8}$ but it was never proved that they decrease blood loss. Nevertheless a significant number of liver centers believe that they do and use them during all liver transplants. The significant incidence of severe hyperfibrinolysis that we found in FAP patients and the dramatic relation observed in these patients between severe hyperfibrinolysis and increased blood loss suggest that the prophylactic use of antifibrinolytic drugs should be evaluated in the future in FAP.

\section{REFERENCES}

1. Ericzon B-G, Suhr O, Broome U, et al: Transplant Proc 27:1233, 1995

2. Kang YG, Lewis JH, Navalgund A, et al: Anesthesiology 66:766, 1987

3. Bakker CM, Metselaar HJ, Groenland TN, et al: Hepatology 48:404, 1992

4. Macedo E, Coutinho P, Morais R, et al: In Isobe T, Araki, Uchino F, et al (eds): Amyloid and Amyloidosis. New York: Plenum Publishing Corp; 1988, p 419

5. Marcel RJ, Stegall WC, Suit CT, et al: Anesth Analg 82:1122, 1996

6. Eleborg L, Suhr O, Gunnarsson L: Amyloid Int J Exp Clin Invest 4:24, 1997

7. Viana JS, Furtado AL: Br J Anaesth 82(suppl 1):41, 1999

8. Grosse H, Lobbes W, Frambach M, et al: Thromb Res 63:287, 1991 